\title{
Ultrasound Methodology for the Synthesis of 2-(4- nitrophenyl)-phenylacetonitrile with Phase-Transfer Catalysis Condition - A Kinetic Study
}

\author{
Annadurai Shoba ${ }^{1}$, Venugopal Rajendran ${ }^{2}$, Varathan Selvaraj $^{3}$ \\ a'Head of the Department of Chemistry, Sri Akilandeswari Women's College, Wandiwash, Tamil Nadu, India - 604408 \\ ${ }^{2}$ Head of the Department of Chemistry, Pachaiyappa's College for Men, Kanchipuram, Tamil Nadu, India-631 501 \\ ${ }^{3}$ Assistant Professor, Department of Chemistry, Sri Akilandeswari Women's College, Wandiwash, Tamil Nadu, India - 604408
}

\section{Graphical Abstract}

Preparation of 2-(4-nitrophenyl)-2-phenylacetonitrile under ultrasound assisted phase-transfer catalysis condition.<smiles>N#CCc1ccccc1</smiles>

2-phenylacetonitrile<smiles>O=[N+]([O-])c1ccc(Cl)cc1</smiles>

1-chloro-4-nitrobenzene
1. BTEAC

\section{Chlorobenzene}

3. $600 \mathrm{rpm}, 40 \mathrm{kHz}, 300 \mathrm{~W}$

4. $30 \mathrm{~min}$.<smiles>N#CC(c1ccccc1)c1ccc([N+](=O)[O-])cc1</smiles>

\section{2-(4-nitrophenyl)-2-phenylacetonitrile}

\begin{abstract}
A single-site phase-transfer catalyst viz., Benzyltriethylammonium chloride (BTEAC) containing the catalytic efficiency of BTEAC was ascertained by comparing with another single-site phase-transfer catalyst viz., tetraethylammonium chloride (TEAC) with ultrasonic irradiation $(40 \mathrm{kHz}, 300 \mathrm{~W})$ performed. The pseudo-first-order kinetic equation was applied to describe the overall reaction under ultrasound irradiation $(40 \mathrm{kHz}, 300 \mathrm{~W})$ in a batch reactor, the yield of product 2-(4-nitrophenyl)-2-phenyl acetonitrile in the organic phase was $98.6 \%$ in 30 min at $65^{\circ} \mathrm{C}$ and $600 \mathrm{rpm}$ with the observed $k_{\text {app }}$ value $\left(\right.$ TEAC: $k_{\text {app }}=5.12 \times 10^{-3}$, min $\left.{ }^{-1}\right)$ almost five fold lesser than Benzyltriethylamminoum chloride BTEAC) $\left(k_{\text {app }}=26.72 \times 10^{-3}\right.$, min $\left.^{-1}\right)$ along with ultrasound irradiation $\left(40 \mathrm{kH}_{z}, 300 \mathrm{~W}\right) . \mathrm{The}^{2}$ present study provides a method to synthesize 2-(4-nitrophenyl)-2-phenyl acetonitrile by ultrasound-assisted liquid-liquid phase transfer catalysis.
\end{abstract}

Keywords: Phase-transfer catalysis; phase-transfer catalyst; ultrasound irradiation; phenylacetonitrile; 1-chloro-4-nitrobenzene

\section{Introduction}

As the chemical reactants reside in immiscible phases, phase- transfer catalysts have the ability to carry out the heterogeneous reactions by one of the reactants penetrating from its normal phase (generally aqueous phase) to the organic phase where the reaction take place, which gives a high conversion and selectivity for the desired product under mild reaction conditions [1]. Ever since [2] found that quaternary onium salts as an effective catalyst for enhancing the two-phase reaction, this methodology occupies an unique niche in organic synthesis and it is a commercially matured discipline with over six hundred applications [3] covering a wide spectrum of industries such as pharmaceuticals, agrochemicals, dyes, perfumes, flavours, specialty polymers, pollution control, etc. As the application of phase-transfer catalysts (PTC) grew, much effort was placed on the development of phase - transfer catalysts with higher catalytic efficiency. To this end, researchers have developed "multi-site" phase-transfer catalysts (MPTC) for much higher activity than normal phase-transfer catalysts. Recently, the catalytic behaviour of multi-site phase-transfer catalysts have been attracted much attention, due to the fact that multiple molecules of the aqueous reactant can be carried into the organic phase once a reaction cycle, thus the catalytic efficiency is enhanced [4 - 6].

Currently, a new analytical and process experimental techniques which are environmental benign techniques viz., ultrasound and microwave irradiation have become immensely popular in promoting various organic reactions [7, 8]. Ultrasound irradiation has been broadly applied in organic synthesis, and shows a good improvement in the reaction rate. When the ultrasonic waves propagate in a liquid solution, the alternate compression and depression are produced to form cavities, within which temperature and pressure can reach $5000 \mathrm{~K}$ and several hundred bars, and the reaction rate is thus enhanced [9-11].

Apparently, the combination of ultrasound irradiation with phase-transfer catalysis might give a synergy effect in promoting the reaction $[12,13]$. The cannizzaro reaction catalyzed by a phase-transfer catalyst under ultrasonic wave of $20 \mathrm{KHz}$ dramatically accelerated the reaction [14]. The liquid-liquid phase-transfer catalyzed 


\section{International Journal of Science and Research (IJSR) \\ ISSN (Online): 2319-7064}

Index Copernicus Value (2015): 78.96 | Impact Factor (2015): 6.391

dichlorocyclopropanation of 1,7-octadiene was reported using benzyltriethylammonium chloride as catalyst assisted by ultrasound irradiation, giving the reaction rate greatly accelerated [15]. The reaction of oximes and dicholoromethane by PTC assisted by ultrasound got $95 \%$ in the silence condition was 16h [16]. Ultrasound irradiation combined with liquid-liquid phase-transfer catalysis reveals a significant improvement in the reaction rate [14 - 17].

C-arylation of phenyl acetonitrle is one of the most widely studied PTC reactions in fine chemical industries which provide pharmaceutically valuable products or intermediates for the synthesis of perfumes, fragrances and plant protection agents $[17-20]$. In the present study, we have synthesized a novel multi-site PTC containing three active sites and its catalytic efficiency was studied through Carylation of phenyl acetonitrle with 1-chloro-4-nitrobenzene assisted by ultrasound were explored.

\section{Experimental}

\subsection{Chemicals}

1-chloro-4-nitrobenzene (SRL), sodium hydroxide (SRL), phenylacetonitrle, diethyl ether, Benzyltriethylamminoum chloride (SRL), ethanol (SRL) was used without further treatment.

\subsection{Instrumentation}

FT-IR Spectra were recorded on a Brucker-Tensor 27 FT-IR spectrophometer. ${ }^{1} \mathrm{H}$ NMR and ${ }^{13} \mathrm{C}$ spectra were recorded on a Bruker $400 \mathrm{MHz}$ and $100 \mathrm{MHz}$ respectively using TMS as an internal standard. Gas chromatography was carried out using a GC-Varian 3700 model. Ultrasonic water bath, Equitron, Media Instrument Manufacturing Company, Chennai, India-600 004.

\section{Ultrasonic Process Equipment}

Ultrasonic energy is transmitted to the process vessel through the liquid medium, usually water in the tank. For safety purpose, the sonochemical reactor consisted of two layers of stainless steel body. The sonochemical reactor configuration used in the present work is basically an ultrasonic bath. The internal dimension of the ultrasonic cleaner tank is $48 \mathrm{~cm} \times 28 \mathrm{~cm} \times 20 \mathrm{~cm}$ with liquid holding capacity of 5 litres with $40 \mathrm{kH}_{\mathrm{z}}, 300 \mathrm{~W}$. The reactor was a $250 \mathrm{~mL}$ three-necked Pyrex round-bottom flask. This reaction vessel was supported at the corner of the ultrasonic cleaning bath $2 \mathrm{~cm}$ above from the position of the transducer to get the maximum ultrasound energy.

\section{Synthesis of 2-(4-nitrophenyl)-2- phenylacetonitrile}

To the mixture of $\mathrm{NaOH}(20 \mathrm{~g}, 0.1449 \mathrm{~mol})$ in water (15 $\mathrm{mL}$ ) and Benzyltriethylamminoum chloride (BTEAB) PTC $\left(0.3 \mathrm{~g}, 4.3859 \times 10^{-4} \mathrm{~mol}\right)$, phenyl acetonitrle $(0.5 \mathrm{~g}, 4.27 \mathrm{x}$ $\left.10^{-3} \mathrm{~mol}\right)$ was added under overhead stirring to generate the anion. Then 1-chloro-4-nitrobenzene $\left(0.80 \mathrm{~g}, 5.09 \times 10^{-3}\right.$ $\mathrm{mol})$ in chlorobenzene $(40 \mathrm{~mL})$ was added slowly. The reaction mixture was heated at $65^{\circ} \mathrm{C}$ for 6 hours with vigorous stirring. The crude product was isolated by simple extraction with diethyl ether $(3 \times 25 \mathrm{~mL})$. The organic layer was collected and the solvent was evaporated under reduced pressure. The crude product was chromatographic $\left(\mathrm{SiO}_{2}\right)$ employing hexane: ethyl acetate $(9: 1)$ as an eluent to obtain a pure monoderivative scheme 1 . The identity of the product was confirmed by ${ }^{1} \mathrm{H}$ NMR and ${ }^{13} \mathrm{C}$ NMR spectra of the product. m.pt. $121-123^{\circ} \mathrm{C}$; Yield: $91 \%$; ${ }^{1} \mathrm{H}$ NMR $\left(300 \mathrm{MH}_{\mathrm{Z}}\right.$, $\left.\mathrm{CDCl}_{3}\right): \delta 5.087(\mathrm{~s}, 1 \mathrm{H}, \mathrm{CH}-\mathrm{CN}), 7.264,8.364(\mathrm{~m}, 9 \mathrm{H}, \mathrm{Ar}-$ CH). ${ }^{13} \mathrm{C}$ NMR $\left(75 \mathrm{MH}_{\mathrm{Z}}, \mathrm{CDCl}_{3}\right): \delta .42 .78(\mathbf{C H}-\mathrm{CN}), 125.54$, $128.68,130.09,130.68,133.45,136.32,142.91,149.86(\mathrm{Ar}-$ $\mathrm{CH})$.

\section{Reaction mechanism and kinetic model}

For synthesizing 2-(4-nitrophenyl)-2-phenylacetonitrile compound, the overall reaction of phenyl acetonitrle and 1chloro-4-nitrobenzene (CNB) was catalysed by the PTC (BTEAC) $\left(\mathrm{Q}^{+} \mathrm{Cl}^{-}\right)$in the aqueous alkaline $(\mathrm{NaOH})$ bi-phase medium and is represented in scheme 2 . The reaction is carried out under PTC assisted ultrasonic irradiation condition. In the current investigation the kinetics was followed in the presence of an excess amount of phenyl acetonitrle and by fixing 1-chloro-4-nitrobenzene as limiting agent. 'The main reason for investigating this reaction is, the effect of low frequency ultrasound irradiation $(40 \mathrm{kHz}$, $300 \mathrm{~W})$ along with agitation speed $(600 \mathrm{rpm})$ to find out the effect of change of $\mathrm{k}_{\text {app }}$ value of this system.

\subsection{Definition}

The conversion $(\mathrm{X})$ of 1-chloro-4-nitrobenzene $(\mathrm{CBN})$ is defines as follows:

$$
\mathrm{X}=1-\left\{[\mathrm{CNB}]_{0} /[\mathrm{CNB}]_{. o, i}\right\}
$$

Where $[\mathrm{CNB}]_{\mathrm{o}}$ and $[\mathrm{CNB}]_{\mathrm{o}, \mathrm{i}}$ represent the concentration of butyl bromide at time (t) $\mathrm{t}=0$ and $\mathrm{t}>0$, respectively.

\subsection{Rate expression}

The rate expression for this reaction may be expressed as ;

$$
-\mathrm{r}_{\mathrm{CNB}}=\mathrm{k}_{\mathrm{app}}[\mathrm{CNB}]_{\mathrm{o}}
$$

Where $k_{a p p}$ is the apparent reaction rate constant. This reaction is carried out in a batch reactor, so the diminution rate of CNB with time (t) can we expressed as

$$
-\mathrm{d}[\mathrm{CNB}]_{0} / \mathrm{dt}=-\mathrm{r}_{\mathrm{CNB}}=\mathrm{k}_{\mathrm{app}}[\mathrm{CNB}]_{\mathrm{o}}
$$

on integrating the Eq. (3) yields:

$$
-\ln \left\{[\mathrm{CNB}]_{0} /[\mathrm{CNB}]_{., \mathrm{i}}\right\}=-\ln (1-\mathrm{X})=\mathrm{k}_{\mathrm{app}}
$$

Using Eq. (4), we can get the $k_{\text {app }}$ value experimentally by plotting $-\ln (1-\mathrm{X})$ against time, $(\mathrm{t})$.

\section{Results and Discussion}

The reaction was conducted on a $250 \mathrm{~mL}$ three-necked Pyrex round-bottom flask which permits agitating the solution, inserting the water condenser to recover organic reactant and taking samples and feeding the reactants. This reaction vessel was suspended at the centre of the sonicator. A known quantity of chlorobenzene (30 mL, solvent), sodium hydroxide $(20 \mathrm{~g}, 0.1447 \mathrm{~mol}), 0.2 \mathrm{~g}$ biphenyl IS,

\section{Volume 6 Issue 7, July 2017




\section{International Journal of Science and Research (IJSR) \\ ISSN (Online): 2319-7064}

Index Copernicus Value (2015): 78.96 | Impact Factor (2015): 6.391

(internal standard) were introduced into the reactor. Then, $0.5 \mathrm{~g}$ of phenyl acetonitrle $\left(4.27 \times 10^{-3} \mathrm{~mol}\right)$ and $0.60 \mathrm{~g}$ of 1 chloro-4-nitrobenzene $\left(3.81 \times 10^{-3} \mathrm{~mol}\right), 3 \mathrm{~mol} \%$ of phasetransfer catalyst BTEAC (with respect to 1-chloro-4nitrobenzene, limiting reagent) were introduced to the reactor to start the reaction. The reaction mixture was stirred at $600 \mathrm{rpm}$. The phase separation was almost immediate on arresting the stirring process. Samples were collected from the organic layer of the mixture (by stopping the stirring for 20-30 seconds each time) at regular time intervals. A pinch of anhydrous $\mathrm{CaCl}_{2}$ was placed in the sample vials to a absorbs any moisture present in the organic layer. Each run consisted of six samples taken over the period ranging from 5 to 30 minutes. The kinetics was followed by estimating the amount of 1-chloro-4-nitrobenzene (limiting reagent) that disappeared using a gas Chromatography (GC-Varian 3700 model). The analyzing conditions were as follows; Column, $30 \mathrm{~m}$ x $0.525 \mathrm{~mm}$ i.d. capillary column containing $100 \%$ poly(dimethyl siloxane); injection temperature, $250^{\circ} \mathrm{C}$; FID detector $\left(280^{\circ} \mathrm{C}\right)$. Yields were determined from standard curve using biphenyl as an internal standard.

\subsection{Effect of stirring speed}

To ascertain the influence of agitation speed on the rate of C-arylation of phenyl acetonitrle, the speed of agitation was varied in the range of 100-1000 rpm along with ultrasound irradiation (40 kHz, 300W) using Benzyltriethylamminoum chloride. The result indicates that the rate of the reaction increases linearly as the agitation speed increases from 100 to $600 \mathrm{rpm}$ (Fig. 1). However, on further increasing the agitation seed from 600 to $1000 \mathrm{rpm}$, there is no significant improvement in the reaction rate constant. This is because the interfacial area per unit volume of dispersion increased linearly with increasing the stirring speed till $600 \mathrm{rpm}$ is reached, where there is no significant increase in the interfacial area per unit volume of dispersion with the corresponding increase in the speed. Thus, increasing the stirring speed changes the particle size of the dispersed phase. Therefore, the agitation speed was set at $600 \mathrm{rpm}$ for studying the reaction phenomena from which the resistance of mass transfer stays at a constant value $[21-26]$. The $\mathrm{k}_{\mathrm{app}}$ values are evaluated from the linear plot of $-\ln (1-\mathrm{X})$ versus time. The results indicate that the mechanical effects brought up by the use of low frequency ultrasounds $(40 \mathrm{kHz}, 300 \mathrm{~W})$ are responsible of the enhancement of the kinetics by harsh mixing, enhancement of mass transfer and so on. Further, when the same reaction was carried out in the presence tetraethylammonium chloride (TEAC) PTC the observed $\mathrm{k}_{\text {app }}$ value (PTC: $\mathrm{k}_{\text {app }}=5.12 \times 10^{-3}, \mathrm{~min}^{-1}$ ) almost five fold lesser than Benzyltriethylamminoum chloride BTEAC) PTC $\left(\mathrm{k}_{\text {app }}=26.72 \times 10^{-3}, \mathrm{~min}^{-1}\right)$ along with ultrasound irradiation (40 kHz, 300W).

\subsection{Effect of the amount of BTEAC and TEAC}

Experiments were conducted by varying the amount of the BTEAC viz., Benzyltriethylamminoum chloride and TEAC viz., tetraethylammonium chloride by keeping other experimental parameters are kept constant. The influence of the amount of TEAC and BTEAC on the C-arylation of phenylacetonitrle has been studied by varying amount of TEAC and BTEAC from $1 \mathrm{~mol} \%$ to $5 \mathrm{~mol} \%$ (with respect to 1-chloro-4-nitrobenzene, limiting reagent) under ultrasound irradiation $(40 \mathrm{kHz}, 300 \mathrm{~W})$. Apparent rate constants were evaluated from the plot of $-\ln (1-\mathrm{X})$ versus time. As shown in Fig. 2, the rate of the reaction increased with increasing mol \% of TEAC \& BTEAC along with ultrasound irradiation $(40 \mathrm{kHz}, 300 \mathrm{~W})$. The $\mathrm{k}_{\text {app }}$ values are linearly dependent on the amount of multi-site phasetransfer catalyst as well as single-site phase-transfer catalyst. The increasing the $\mathrm{k}_{\mathrm{app}}$ value is attributed to the positive effect of ultrasound might be enlarged [27].

\subsection{Effect of the concentration of 1-chloro-4- nitrobenzene}

To investigate the influence of 1-chloro-4-nitrobenzene (CNB) on the kinetics of synthesis of 1-chloro-4nitrobenzene under ultrasonic irradiation condition $(40 \mathrm{kHz}$, $300 \mathrm{~W}$ ), the amount of CNB was varied from $0.2 \mathrm{~g}$ to $0.8 \mathrm{~g}$. The results are shown in (Table-1). The data clearly indicates that the $\mathrm{k}_{\mathrm{app}}$ value increases with increasing the amount of 1-chloro-4-nitrobenzene. When the 1-chloro-4nitrobenzene concentration increased, the probability of finding the substrate with active-site of the catalyst and ultrasound enhanced the rate of the reaction [27]. It may be due to reduces the surface area between the aqueous and organic phases, and hence more reactants collide to each other simultaneously we get higher $\mathrm{k}_{\mathrm{app}}$ value.

\subsection{Effect of temperature}

The effect of temperature on the reaction between phenyl acetonitrle and 1-chloro-4-nitrobenzene was studied under otherwise similar conditions. The temperature was varied from 30 to $80^{\circ} \mathrm{C}$. The kinetic profile of the reaction is obtained by plotting $-\ln (1-\mathrm{X})$ versus time. It is obvious that the reactivity is increased with an increase in the temperature along with ultrasonic effect [28]. The reason is that the number of reactant molecules which possess higher activation energy at a higher temperature and thus the ultrasonic wave easily passes through the reactor. The other point is that the collision of the reactants at higher temperature is also increased. Hence, the apparent rate constant is increased at higher temperature. Arrhenius plots were made in Fig.3 of $-\ln \mathrm{k}_{\text {app }}$ against $1 / \mathrm{T}$ to get activation energy of $52.16 \mathrm{~kJ} \cdot \mathrm{mol}^{-1}$.

From the literature survey, the dehydrobromination of (2bromoethyl) benzene catalyzed by tetraoctylammonium bromide (TOAB), an extraction mechanism was proposed [29] due to lower Ea value $\left(<43 \mathrm{~kJ} \mathrm{~mol}^{-1}\right)$. In general, higher activation energy (more than $43 \mathrm{~kJ} \mathrm{~mol}^{-1}$ ) suggests an interfacial mechanism [30]. The activation energy for the heterogeneous ethylation of phenylactonitrile was reported to be $53.64 \mathrm{~kJ} \mathrm{~mol}^{-1}$ and for this an interfacial mechanism was proposed [31]. Further, in the $\mathrm{N}$-alkylation of pyrrolidine-2-one, the Ea $\left(51.35 \mathrm{~kJ} . \mathrm{mol}^{-1}\right)$ was reported by Sasson and Bilman [32], and for this reaction they proposed an interfacial mechanism. They concluded that the deprotonation of the substrate takes place at the interphase and consequently the organic anion is extracted and reacts in the bulk of the organic phase. The rate-determining step in the process is the anion exchange at the interphase. In our study, the observed $\mathrm{E}_{\mathrm{a}}$ value is $52.36 \mathrm{~kJ}^{\mathrm{mol}}{ }^{-1}$. Hence, we

\section{Volume 6 Issue 7, July 2017 www.ijsr.net}




\section{International Journal of Science and Research (IJSR) \\ ISSN (Online): 2319-7064}

Index Copernicus Value (2015): 78.96 | Impact Factor (2015): 6.391

proposed an interfacial mechanism for our present study [30 - 33].

\subsection{Influence of amount of water}

Fig.4 shows the effect of water on the formation of the product under ultrasound irradiation condition $(40 \mathrm{kHz}$, $300 \mathrm{~W})$. The observed $\mathrm{k}_{\text {app }}$ value directly affects both the concentration of sodium hydroxide in the aqueous phase and generation of anions on increasing the volume of water, the concentration of alkali compound in aqueous solution is decreases from 20 to $40 \mathrm{~mL}$. From the literature, the kinetic study of the phase-transfer catalyzed etherification of 4,4'bis(chloromethyl)-1,1'-biphenyl with phenol in an alkaline solution of potassium hydroxide/organic solvent two-phase medium, similar decrease in rate of the reaction on corresponding increase in volume of water was reported [33, 34].

\subsection{Effect of Ultrasound}

Ultrasonic irradiation is defines as acoustic waves with frequencies in the $20 \mathrm{kHz}-100 \mathrm{MHz}$ range [35, 36]. They create cavities generating locally high temperature and pressures [61-64] or strong electric fields [35 - 37]. Ultrasound is known to accelerate diverse types of organic reactions and it is established in many organic reactions, which are otherwise slow due to poor mass transfer which is by sonication due to cavitation [38]. It has been reported that a combination of PTC and ultrasound is often better than either of the two techniques alone [39].

To ascertain the influence of ultrasonic frequencies on the rate of C-arylation of phenyl acetonitrle with output power of $300 \mathrm{~W}$, the ultrasonic frequency was $40 \mathrm{kHz}$ under otherwise similar conditions using BTEAC and TEAC as the catalyst. The kinetic profile of the reaction is obtained by plotting $-\ln (1-\mathrm{X})$ against time. In our experimental condition at 30 minutes, TEAC the $\mathrm{k}_{\text {app }}$ values is $5.12 \times 10^{-3}, \mathrm{~min}^{-1}$ but in the presence BTEAC condition the $\mathrm{k}_{\text {app }}$ values are 26.72 $\mathrm{x} 10^{-3}, \mathrm{~min}^{-1}$, respectively (Table-2). The $\mathrm{k}_{\text {app }}$ value of BTEAC was about five times higher than that of TEAC. It may be due to the quaternary onium phase-transfer catalyst, $\mathrm{Q}^{+} \mathrm{X}^{-}$generally contains an active centre $\left(\mathrm{C}-\mathrm{N}^{+}\right)$, that carries only one molecule of reactant $\mathrm{Na}^{+} \mathrm{OH}^{-}(\mathrm{MY})$ in the form of catalytic intermediate $\mathrm{Q}^{+} \mathrm{OH}^{-}(\mathrm{QY})$ once a reaction cycle, then QY transferring from the aqueous phase into the inter phase/organic phase. When more than one active centre contained in a catalyst molecule of (MY) can be carried to react in a reaction cycle. In addition, ultrasound irradiation enhances the heterogeneous system may act as homogeneously, hence we get higher $\mathrm{k}_{\text {app }}$ value compared with conventional method [38-41].

\subsection{Effect of organic solvents}

In this work, the influence of various organic solvents on the rate of C-arylation of phenyl acetonitrle was followed under otherwise standard reaction conditions. Five organic solvents employed in this study are toluene, anisole, cyclohexane, chlorobenzene, and n-hexane. From the plot of $-\ln (1-\mathrm{X})$ against time, the $\mathrm{k}_{\text {app }}$ values are shown in the Table-3. From the Table-3, chlorobenzene possesses a higher $\mathrm{k}_{\text {app }}$ value among the five organic solvents, due to its higher dielectric constant. In another view the ultrasonic irradiation can enhance the rate in the presence of more polar solvents due to passing higher ultrasonic waves to the reactor and makes fruitful collision between the reactants, and hence we get higher $k_{\text {app }}$ value for chlorobenzene solvent of this system and also this statement is not always true [42 - 44].

\subsection{Effect of varying sodium hydroxide concentrations}

In the PTC / base catalyzed reactions, the reaction rate is known to be greatly affected by a concentration of the alkaline compound. The rate of $\mathrm{C}$-arylation of phenyl acetonitrle strongly depends on the strength of the sodium hydroxide. Kinetic experiments were carried out, by employing 20 to $40 \mathrm{~g}$ of $\mathrm{NaOH}$ under similar reaction conditions. The Kinetic profile of the reaction is obtained by $-\ln (1-\mathrm{X})$ against time. The $\mathrm{k}_{\mathrm{app}}$ values tremendously increased with increasing in basicity of $\mathrm{OH}^{-}$ion (Table 4). It suggest that the $\mathrm{OH}^{-}$ions which are less solvated by water molecules and there by the $\mathrm{k}_{\mathrm{app}}$ value increases $[45,46]$.

\section{Mechanism}

In the present investigation, the dependency of rate of Carylation of phenyl acetonitrle on stirring speed, [catalyst], $[\mathrm{NaOH}]$, temperature and the higher activation energy $(\mathrm{Ea})$ has suggested that the reaction proceeds through interfacial mechanism. The interfacial mechanism for the reactions of carbanions with a variety of electrophiles was proposed by Makosza [46]. A crucial point is the formation of the carbanion by proton abstraction from the $\mathrm{CH}$ acid dissolved in a nonpolar solvent by the concentrate aqueous $\mathrm{NaOH}$ at the phase boundary. The generated carbanions, as sodium derivatives, remain adsorbed at the surface of the aqueous phase. They cannot migrate into the organic phase. The catalyst, a lipophilic cation, exchanges anions at the interface, and the new "fully lipophilic" ion-pair migrates into the organic phase where the reaction occurs. The free catalyst can, again, undergo the ion exchange at the interface. Rabinovitz et al. [47] reviewed the interfacial mechanism of hydroxide ion initiated alkylation in presence of PTC. In view of the early results and observation, the mechanism for C-arylation of phenylacetonitrle with 1chloro-4-nitrobenzene under liquid-liquid biphase condition involves the following steps:

1) The organic phase substrate phenyl acetonitrle is deprotonated at the interface by the aqueous phase $\mathrm{NaOH}$ and forming an ion-pair $\left[\mathrm{Na}^{+} \mathrm{R}^{-}\right]$.

2) This ion-pair $\left[\mathrm{Na}^{+} \mathrm{R}^{-}\right]$at the interface reacts with the catalyst MPTC $\left(\mathrm{Q}^{+} \mathrm{Br}^{-}\right)$to form $\left[\mathrm{Q}^{+} \mathrm{R}^{-}\right]$catalyst-anion pair.

3) The paired anion $\left[Q^{+} R^{-}\right]$moved into the organic phase and then reacts with the arylating agent 1-chloro-4nitrobenzene to form the arylated product 2-(4nitrophenyl)-2-phenylacetonitrile and the catalyst return to its original form of $\mathrm{Q}^{+} \mathrm{Cl}^{-}$(aqueous phase).

\section{Conclusion}

The arylation of phenylacetonitrile with 1-choloro-4nitrobenzene catalyzed by the prepared TEAC and BTEAC,

\section{Volume 6 Issue 7, July 2017 www.ijsr.net}




\section{International Journal of Science and Research (IJSR) \\ ISSN (Online): 2319-7064}

Index Copernicus Value (2015): 78.96 | Impact Factor (2015): 6.391

PTC were studied via ultrasound assisted liquid-liquid phase-transfer catalysts in a batch reactor. The reaction mechanism and the apparent rate constants were obtained from the experimental results, the apparent rate constants are found to be directly dependent on each kinetic variables, viz., [BTEAC], [TEAC], [NaOH], ultrasonic frequency, stirring speed and temperature. However it decreases with increase in volume of water. Energy of activation was calculated from the Arrhenius plot. Based on the experimental evidence, an interfacial mechanism has been proposed. Combination of TEAC \& BTEAC with ultrasound irradiation resulted in better efficacy as compared to the individual operations.

\section{Acknowledgments}

The authors would like to Thank, Sri Akilandeswari Women's College, Wandiwash, Tamil Nadu, India - 604 408 and Pachaiyappa's Trust, Chennai, Tamil Nadu, India600030 for their grant of permission to do this research work.

\section{References}

[1] G.D. Yadav, Insight into green phase - transfer catalysis, Top. Catal. 29 (2004) 145-161.

[2] Z. Yang, H. Zhou, H. Ji, Mechanism into selective oxidation of cinnamaldehyde using beta-cyclodextrin polymer as phase-transfer catalyst, Tetrahedron 68 (2012) 5912-5919.

[3] H.O. Bourbigou, L. Magna, D. Morvan, Ionic liquids and Catalysis: Appl. Catal. A: Gen. 373 (2010) 1 - 56.

[4] J.P. Jayachandran, M.L. Wang, Cycloalkylation of phenylacetonitrile with 1,4-dibromobutane catalyzed by aqueous sodium hydroxide and a new phase transfer reagent, Dq-Br, Appl. Catal. A: Gen. 198 (2000) 127 137.

[5] H.E. Ali, cycloalkylation reaction of fatty amines with a alpha-dihaloalkanes role of bis-quaternary ammonium salts as phase-transfer catalysts, Catal. Commun.8 (2007) 855 .

[6] Y.M. Yang, D.W. Lin, Third-liquid phase-transfer catalysed esterification of sodium benzoate with novel dual-site phase-transfer catalyst under ultrasonic irradiation, Catal. Commun. 14 (2011) 10-106.

[7] A. Loupy, A. Petit. J. Hamelin, F.T. Boullet, P. Jacquault, D. Mathe, New solvent-free organic synthesis using focused microwaves, Synthesis (1998) 12131234.

[8] S.F. Escudero, E.P. Rondon, V.C. Casilda, B. Casal, R. M. M. Aranda, A.J.L. Peinado, C.J.D. Valle, The effect of ultrasound on the $\mathrm{N}$-alkylation of imidazole over alkaline carbons: Kinetic aspects, Appl. Catal. A: Gen. 378 (2010) $26-32$.

[9] T.J. Mason, J.P. Lorimer, Sonochemistry, Theory Applications and Uses of Ultrasound in Chemistry, Ellis Horwood Ltd. John Wiley and Son, 1988.

[10] J.L Luche, synthetic organic chemistry, New York: plenum press; 1998.

[11]T.J. Mason, Ultrasound in synthetic organic chemistry, Chem. Soc. Rev. 26 (1997) 443-451.

[12] G. Cravotto, G. Palmisano, S. Tollari, G.M. Nano, A. Penoni, The Suzuki homocoupling reaction under high- intensity ultrasound, Ultrason. Sonochem. 12 (2005) 91 94.

[13] R. Cella, H.A. Stefani, Ultrasound-assisted synthesis of $\mathrm{Z}$ and $\mathrm{E}$ stilbenes by Suzuki cross-coupling reactions of organotellurides with potassium organotrifluoroborate salts, Tetrahedron 62 (2006) 5656-5662.

[14] M.H. Entezari, A.A. Shamel; phase-transfer catalysis and ultrasonic waves-1, cannizaro reaction, Ultrason. Sonochem. 7 (2000) 169-172.

[15]M.L. Wang, V. Rajendran, Kinetics for dichlorocyclopropanation of 1,7-octadiene under the influence of ultrasound assisted phase-transfer catalysis condition. J. Mol. Catal. A: Chem. 273 (2007) 5-13.

[16] J.T. Li, X.L. Li; , an efficient and practical synthesis of methylene dioximes by combination of ultrasound and phase-transfer catalyst. Ultrason. Sonochem. 14 (2007) 677-679.

[17] M.L. Wang, V. Rajendran, A kinetic study of thioether synthesis under influence of ultrasound assisted phasetransfer catalysis conditions. J. Mol. Catal. A: Chem. 244 (2006) 237-243.

[18] M.L. Wang, V. Rajendran, Ultrasound assisted phasetransfer catalytic epoxidation of 1.7-octadiene - A kinetic study, Ultrason. Sonochem. 14 (2007) 46-54.

[19] R.D. Acker, Tetrahedron Lett. 19 (1978) 2399-2402.

[20] Y. Tanigawa, H. Ohta, A. Sonoda, S.I. Murahashi, J. Am. Chem. Soc. 100 (1978) 4610-4612.

[21]H.M. Yang, G.Y. Peng, Ultrasound-assisted third-liquid phase-transfer catalyzed esterification of sodium salicylate in a continuous two-phase-flow reactor, Ultrason. Sonochem. 17 (2010) 239-245.

[22] M.L. Wang, C.J. Chen, Kinetic Study of Synthesizing 1-(3-Phenylpropyl) pyrrolidine-2,5-dione under solidliquid phase-transfer catalytic conditions assisted by ultrasonic irradiation, Org. Process Res. Dev. 14 (2010) 737-745.

[23]H.M. Yang, C.C. Li, Kinetics for synthesizing benzyl salicylate by third-liquid phase-transfer catalysis, J. Mol. Catal. A: Chem., 246 (2006) 255 - 262.

[24] M. Rabonivitz, Y. Sasson, M. Halpern, Hydroxide ion initiated reactions under phase-transfer-catalysis conditions-5. Isomerization of allylbenzene via hydroxide ion extraction. J. Org. Chem. 48 (1983) 1022-1025.

[25]H.H. Liu, Y. Wang, Y. J. Shu, X.G. Zhou, J. Wu, and S.Y. Yan, Cyclopropanation of alkenes catalyzed metallophthalocyanines, J. Mol. Catal. A: Chem., 246 (2006) $49-52$.

[26] M.L. Wang, Y.M. Hsieh, R.Y. Chang, Kinetic study of diclorocyclopropanation of 1, 7-octadiene under phasetransfer catalysis conditions at high alkaline concentration, Ind. Eng. Chem. Res. 42 (2003) 47024707.

[27] M.L. Wang, V. Rajendran, Ethoxylation of pchloronitrobenzene using phase-transfer catalysts by ultrasound irradiation -A kinetic study, Ultrason. Sonochem. 14 (2007) 368-374.

[28] H.S. Wu, J.J. Lai, Phenoxide Allylation in a PhaseTransfer Catalytic Extraction System, Ind. Eng. Chem. Res. 34 (1995) 1536-1538.

[29] M. Halpern, Y. Sasson, M. Rabinovitz, Hydroxide-ion initiated reactions under phase-transfer catalysis conditions. J. Org . Chem. 49 (1984) 2011-2012. 


\section{International Journal of Science and Research (IJSR) \\ ISSN (Online): 2319-7064 \\ Index Copernicus Value (2015): 78.96 | Impact Factor (2015): 6.391}

[30] V. Rajendran, M.L. Wang, Dichlorocarbene addition to allyl phenyl ether under phase - transfer catalysis conditions - A kinetic study, J. Mol. Catal. A: Chem. 288 (2008) 23-27.

[31]E. Chiellini, R. Solaro, S.D. Antone, Heterogeneous ethylation of phenylacetonitrile, J. Org. Chem. 45 (1980) 4179-4183.

[32] Y. Sasson, N. Bilman, Mechanism of solid/liquid phase - transfer catalysis in the presence of sodium hydroxide: Alkylation of 2-pyrrolidinone, J. Chem. Soc., Perkin Trans.2 (1989) 2029-2033.

[33] M.L. Wang, Z.F. Lee, Reaction of 4,4'-bis (chloromethyl)-1,1'-biphenyl and phenol in two-phase medium via phase-transfer catalysis, J. Mol. Catal. A: Chem. 264 (2006) 119-127.

[34] M.A. Margulis, Sonochemistry as a new promising area of high energy chemistry, High Energ. Chem. 38 (2004) 135-142.

[35] T.J. Mason, J.P. Orimer, Applied Sonochemistry: The Uses of Power Ultrasound in Chemistry and Processing, Wiley-VCH, 2002.

[36] V. Polackova, M. Hutka, S. Toma, Ultrasound effect on Suzuki reactions. 1. Synthesis of unsymmetrical biaryls, Ultrason. Sonochem. 12 (2005) 99-102.

[37] G.V. Ambulgekar, B.M. Bhanage, S.D. Samant, Low temperature recyclable catalyst for Heck reactions using ultrasound, Tetrahedron Lett. 46 (2005) 2483-2485.

[38] T. Lepoint, F. Mullie, What exactly is cavitation chemistry? Ultrason. Sonochem. 1 (1994) S13-S22.

[39] T.J. Mason, Industrial sonochemistry: Potential and practicality, Ultrasonics 30 (1992) 192-196.
[40] M.H. Entezari, A. Heshmati, A.S. Yazdi, A combination of ultrasound and inorganic catalyst: removal of 2chlorophenol from aqueous solution, Ultrason. Sonochem. 12 (2005) 137-141.

[41] M.L. Wang, W.H. Chen, Kinetic study of synthesizing dimethoxydiphenylmethane under phase-transfer catalysis and ultrasonic irradiation, Ind. Eng. Chem. Res. 48 (2009) 1376-1383.

[42] M.L. Wang, V. Rajendran, Kinetics for dichlorocyclopropanation of 1,7- octadiene under the influence of Ultrasound assisted phase-transfer catalysis condition, J. Mol. Cat. A: Chem. 273 (2007) 5-13.

[43]D. Landini, A. Maia, A. Rampoldi, Extractability and reactivity of hydroxide ion in low-polarity media under phase-transfer catalysis conditions: dramatic effect of the aqueous base concentration, J. Org. Chem. 51 (1986) 5475-5476.

[44]P.A. Vivekanandan, M.L. Wang. Kinetic for Sonocatalyzed synthesis of 2- phenylvaleronitrile under controlled reaction conditions. Catal. Commun., 18 (2011) 1241-1248.

[45] M. Makosza, E. Bialecka, Reactions of organic anion x. LXXIIL Alkylation of phenylacetonitrile at the interface with aqueous sodium hydroxide, Tetrahedron Lett. 18 (1977) 183-186.

[46] M. Makosza, Pure Appl. Chem. 43 (1975) 439-462.

[47] M. Rabinovitz, Y. Cohen, M. Halpern, Angew. Chem. Int. Ed. Engl. 25 (1986) 960-970.

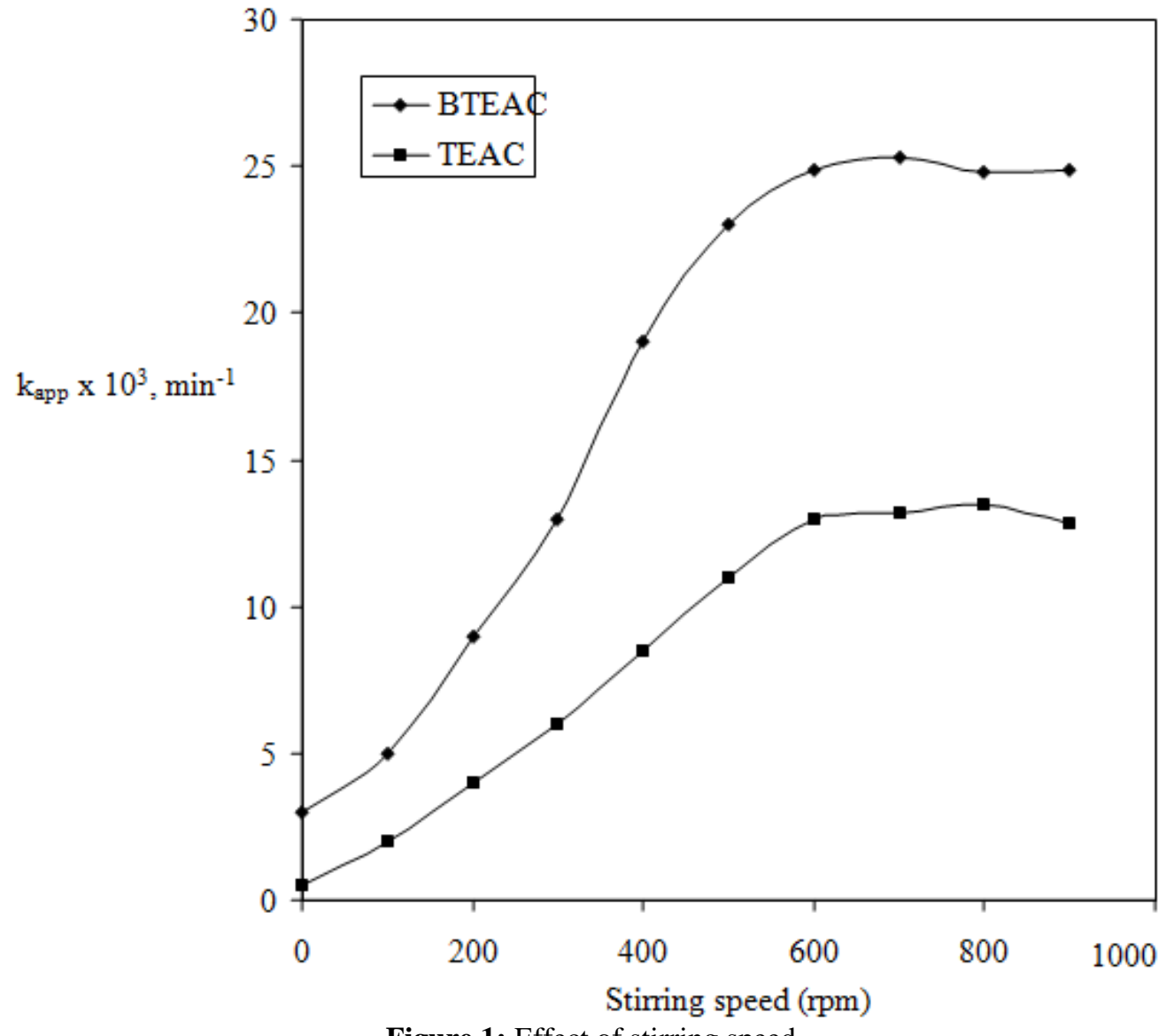

Figure 1: Effect of stirring speed 


\section{International Journal of Science and Research (IJSR) \\ ISSN (Online): 2319-7064}

Index Copernicus Value (2015): 78.96 | Impact Factor (2015): 6.391

\section{Figure 1}

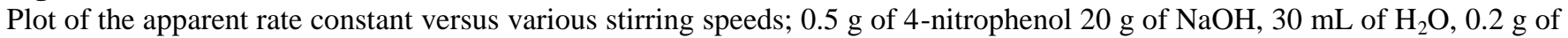
internal standard (biphenyl), $0.6 \mathrm{~g}$ of1-chloro-4-nitrobenzene, $3 \mathrm{~mol} \%$ of BTEAC, $30 \mathrm{~mL}$ of chlorobenzene, $30 \mathrm{~min}, 65^{\circ} \mathrm{C}$; ultrasound conditions $(40 \mathrm{kHz}, 300 \mathrm{~W})$.

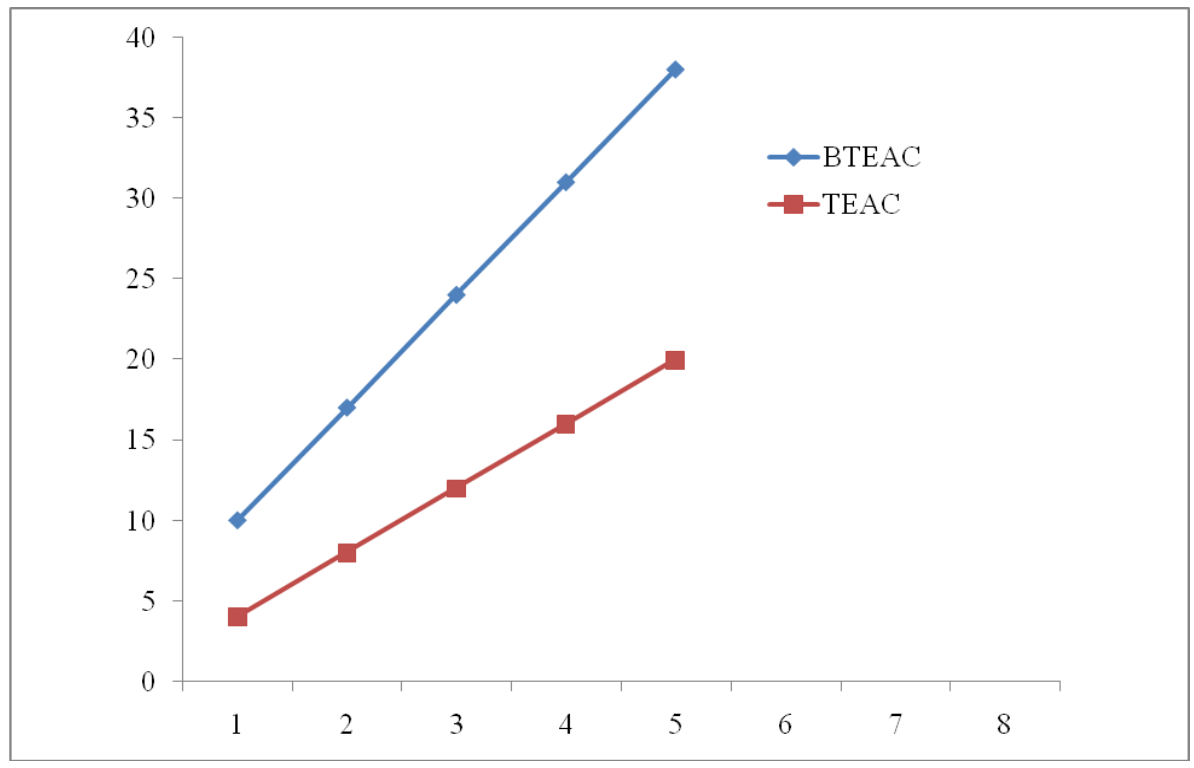

Figure 2: (Effect of BTEAC and TEAC)

\section{Figure 2}

Effect of the amount of BTEAC on the apparent rate constant: $0.5 \mathrm{~g}$ of 4-nitrophenol $20 \mathrm{~g}$ of NaOH, $30 \mathrm{~mL} \mathrm{of} \mathrm{H}_{2} \mathrm{O}, 0.2 \mathrm{~g}$ of internal standard (biphenyl), $0.6 \mathrm{~g}$ of 1-chloro-4-nitrobenzene, $0.3 \mathrm{~g}$ of BTEAC, $30 \mathrm{~mL}$ of chlorobenzene, $65^{\circ} \mathrm{C}$; ultrasound conditions $(40 \mathrm{kHz}, 300 \mathrm{~W})$.

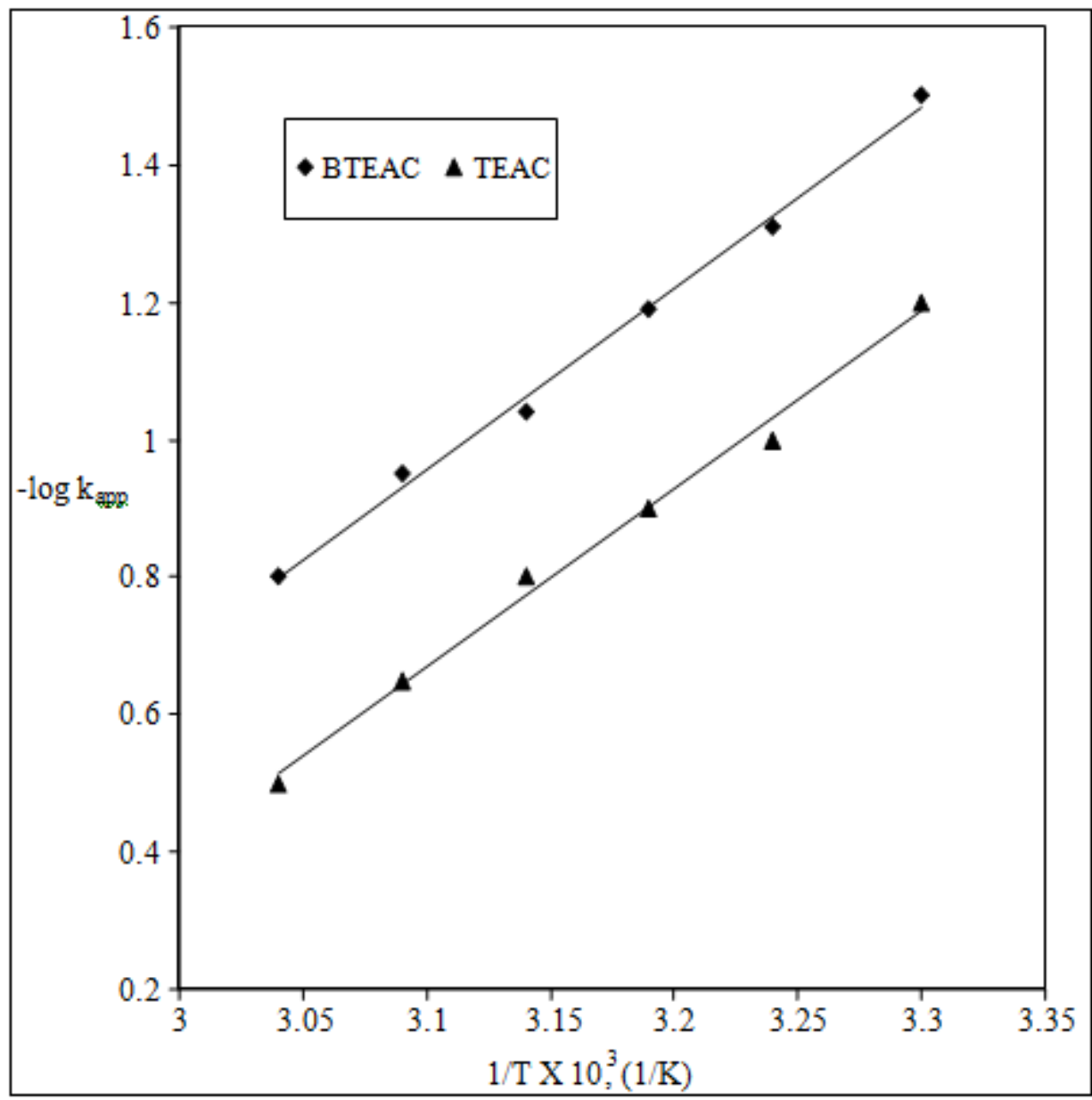

Figure 3: (Effect of Temperature)

Volume 6 Issue 7, July 2017

www.ijsr.net 


\section{International Journal of Science and Research (IJSR) \\ ISSN (Online): 2319-7064}

Index Copernicus Value (2015): 78.96 | Impact Factor (2015): 6.391

\section{Figure 3}

Arrhenius plot; $0.5 \mathrm{~g}$ of 4-nitrophenol $20 \mathrm{~g}$ of $\mathrm{NaOH}, 30 \mathrm{~mL}$ of $\mathrm{H}_{2} \mathrm{O}, 0.2 \mathrm{~g}$ of internal standard (biphenyl), $0.6 \mathrm{~g}$ of 1-chloro-4nitrobenzene, $0.3 \mathrm{~g}$ of BTEAC, $30 \mathrm{~mL}$ of chlorobenzene, $65^{\circ} \mathrm{C}$; ultrasound conditions $(40 \mathrm{kHz}, 300 \mathrm{~W})$.

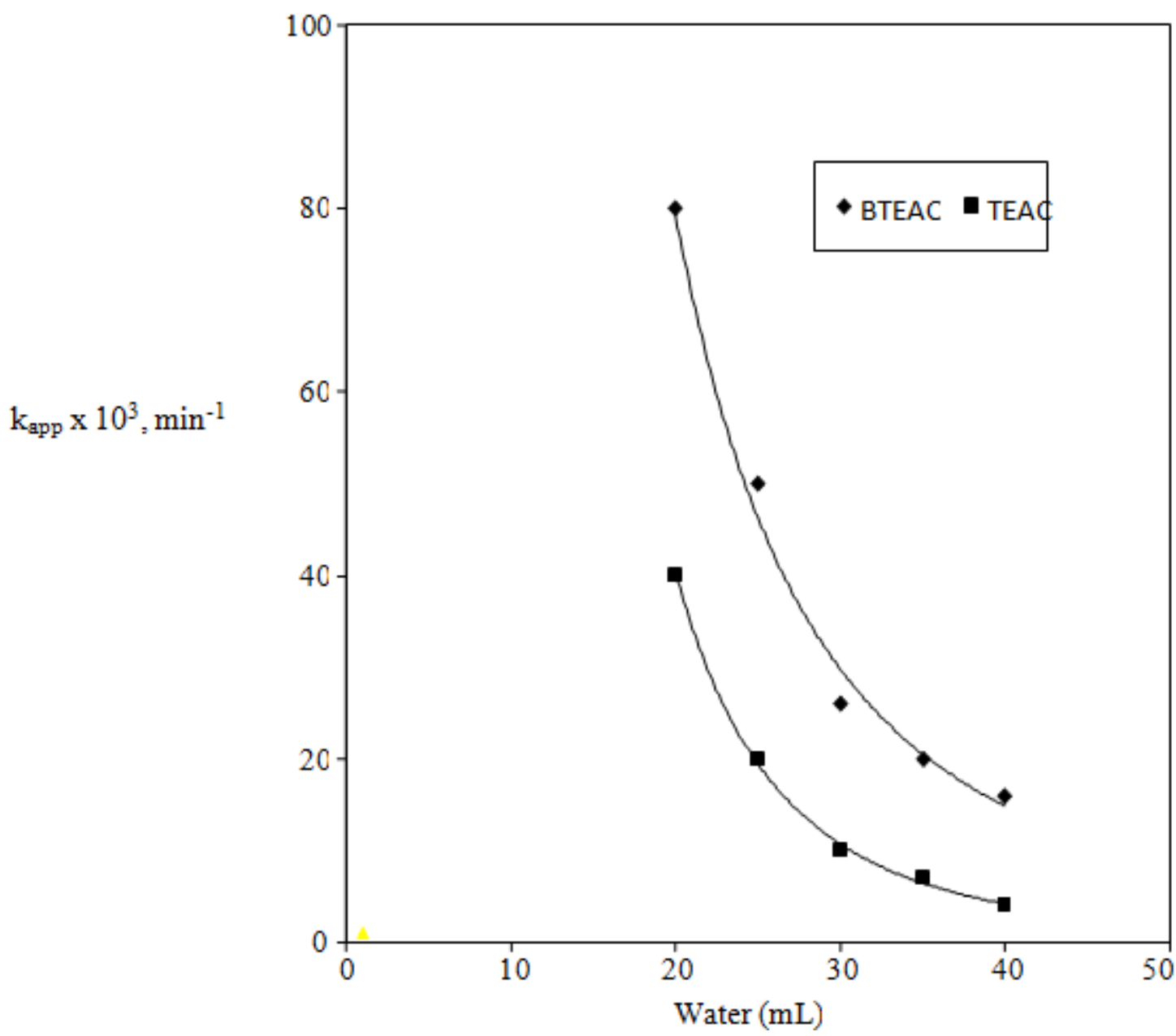

Figure 4: (Effect of amount of water)

\section{Figure 4}

Plot of the apparent rate constants versus different volumes of water; $0.5 \mathrm{~g}$ of 4-nitrophenol $20 \mathrm{~g}$ of $\mathrm{NaOH}, 30 \mathrm{~mL} \mathrm{of} \mathrm{H}_{2} \mathrm{O}, 0.2$ $\mathrm{g}$ of internal standard (biphenyl), $0.6 \mathrm{~g}$ of 1-chloro-4-nitrobenzene, $0.3 \mathrm{~g}$ of BTEAC, $30 \mathrm{~mL}$ of chlorobenzene, $65^{\circ} \mathrm{C}$; ultrasound conditions $(40 \mathrm{kHz}, 300 \mathrm{~W})$.

Table 1: Effect of the amount of 1-chloro-4-nitrobenzene

\begin{tabular}{|c|c|c|}
\hline 1-chloro-4-nitrobenzene (CNB), g & $\begin{array}{c}\mathrm{k}_{\mathrm{app}} \times 10^{3}, \mathrm{~min}^{-1} \\
\text { BTEAC }\end{array}$ & $\begin{array}{c}\mathrm{k}_{\mathrm{app}} \times 10^{3}, \mathrm{~min}^{-1} \\
\text { TEAC }\end{array}$ \\
\hline 0.2 & 17.68 & 3.08 \\
0.4 & 21.44 & 4.66 \\
0.6 & 26.72 & 5.12 \\
0.7 & 31.82 & 6.02 \\
0.8 & 36.41 & 7.22 \\
\hline
\end{tabular}

Effect of amount of 1-chloro-4-nitrobenzene $(\mathrm{CNB})$ on the rate of 1-chloro-4-nitrobenzene of phenylacetonitrle under ultrasonic condition: $20 \mathrm{~g}$ of $\mathrm{NaOH}, 30 \mathrm{~mL}$ of $\mathrm{H}_{2} \mathrm{O}, 0.2 \mathrm{~g}$ of internal standard (biphenyl), $0.3 \mathrm{~g}$ of $\mathrm{BTEAC}, 30 \mathrm{~mL}$ of chlorobenzene, $600 \mathrm{rpm}, 30 \mathrm{~min}, 65^{\circ} \mathrm{C}$; ultrasound conditions $(40 \mathrm{kHz}, 300 \mathrm{~W})$.

Table 2: Effect of ultrasonic frequency

\begin{tabular}{|c|l|c|}
\hline $\begin{array}{c}\text { Ultrasonic frequency } \\
(40 \mathrm{kHz}, 300 \mathrm{~W})\end{array}$ & TEAC & BTEAC \\
\hline $\mathrm{k}_{\mathrm{app}} \times 10^{3}, \mathrm{~min}^{-1}$ & 5.12 & 26.72 \\
\hline
\end{tabular}




\section{International Journal of Science and Research (IJSR) \\ ISSN (Online): 2319-7064 \\ Index Copernicus Value (2015): 78.96 | Impact Factor (2015): 6.391}

Influence of ultrasonic frequencies on the rate of 1-chloro-4-nitrobenzene of phenyl acetonitrle under ultrasonic condition: $20 \mathrm{~g}$ of $\mathrm{NaOH}, 30 \mathrm{~mL}$ of $\mathrm{H}_{2} \mathrm{O}, 0.2 \mathrm{~g}$ of internal standard (biphenyl), $0.3 \mathrm{~g}$ of BTEAC, $0.6 \mathrm{~g} \mathrm{1-chloro-4-nitrobenzene,} 30 \mathrm{~mL}$ of chlorobenzene, $600 \mathrm{rpm}, 30 \mathrm{~min}, 65^{\circ} \mathrm{C}$.

Table 3: Effect of organic solvents

\begin{tabular}{|c|c|c|c|c|c|}
\hline & \multicolumn{5}{|c|}{ Solvents } \\
\cline { 2 - 6 } & Cyclohexane & n-Hexane & Toluene & Anisole & Chlorobenzene \\
\hline $\mathrm{z}^{\mathrm{a}}$ (Dielectric constant) & 2.02 & 2.28 & 2.31 & 4.30 & 5.60 \\
\hline $\begin{array}{c}\mathrm{k}_{\mathrm{app}} \times 10^{3}, \mathrm{~min}^{-1} \\
\text { BTEAC }\end{array}$ & 12.72 & 13.62 & 18.05 & 19.96 & 26.72 \\
\hline $\begin{array}{c}\mathrm{k}_{\mathrm{app}} \times 10^{3}, \mathrm{~min}^{-1} \\
\text { TEAC }\end{array}$ & 2.33 & 2.54 & 3.63 & 3.92 & 5.12 \\
\hline
\end{tabular}

Influence of organic solvents on the rate of 1-chloro-4-nitrobenzene of phenyl acetonitrle under ultrasonic condition: $20 \mathrm{~g}$ of $\mathrm{NaOH}, 30 \mathrm{~mL}$ of $\mathrm{H}_{2} \mathrm{O}, 0.2 \mathrm{~g}$ of internal standard (biphenyl), $0.3 \mathrm{~g}$ of BTEAC, $0.6 \mathrm{~g}$ 1-chloro-4-nitrobenzene, $600 \mathrm{rpm}, 30 \mathrm{~min}$, $65^{\circ} \mathrm{C}$; ultrasound conditions $(40 \mathrm{kHz}, 300 \mathrm{~W})$.

Table 4: Effect of sodium hydroxide

\begin{tabular}{|c|c|c|}
\hline Amount of $\mathrm{NaOH}(\mathrm{g})$ & $\begin{array}{c}k_{\text {sso }} \times 10^{3}, \mathrm{~min}^{-1} \\
\text { BTEAC }\end{array}$ & $\begin{array}{c}k_{\text {sos }} \times 10^{3}, \mathrm{~min}^{-2} \\
\text { TEAC }\end{array}$ \\
\hline 10 & 16.22 & 3.09 \\
15 & 20.9 & 4.23 \\
20 & 26.72 & 5.12 \\
25 & 30.46 & 6.02 \\
30 & 34.33 & 6.76 \\
\hline
\end{tabular}

Influence of alkalinity on $\mathrm{k}_{\mathrm{app}}$ in the 1-chloro-4-nitrobenzene of phenyl acetonitrle under ultrasonic condition: $0.2 \mathrm{~g}$ of internal standard (biphenyl), $0.3 \mathrm{~g}$ of BTEAC, $0.6 \mathrm{~g}$ 1-chloro-4-nitrobenzene, $30 \mathrm{~mL}$ of chlorobenzene, $600 \mathrm{rpm}, 30 \mathrm{~min}, 65^{\circ} \mathrm{C}$; ultrasound conditions $(40 \mathrm{kHz}, 300 \mathrm{~W})$.<smiles>N#CCc1ccccc1</smiles>

2-phenylacetonitrile<smiles>O=[N+]([O-])c1ccc(Cl)cc1</smiles>

1-chloro-4-nitrobenzene
1. BTEAC

2. Chlorobenzene

3. $600 \mathrm{rpm}, 40 \mathrm{kHz}, 300 \mathrm{~W}$

4. $30 \mathrm{~min}$.

2-(4-nitrophenyl)-2-phenylacetonitrile 


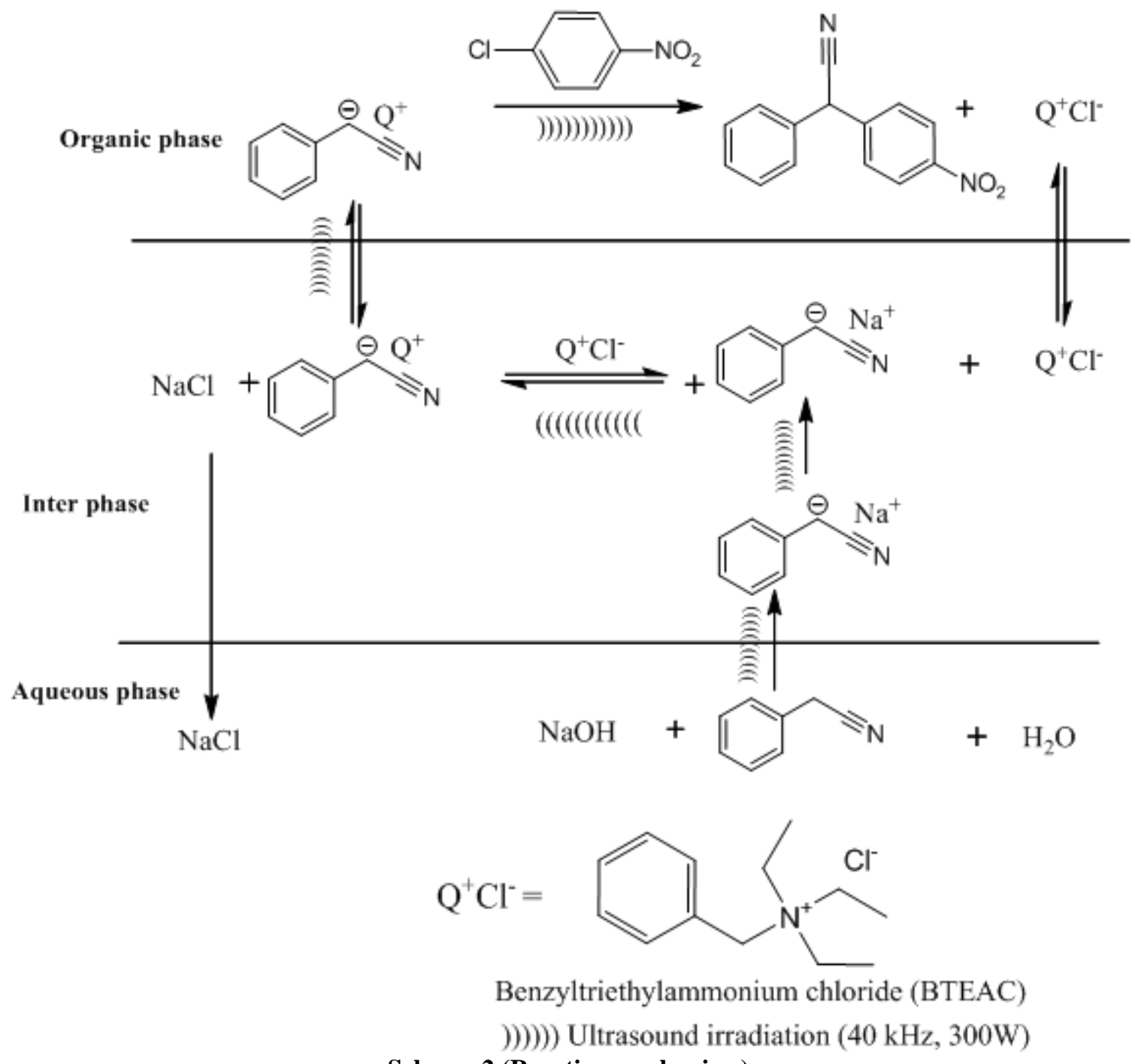

Scheme-2 (Reaction mechanism) 


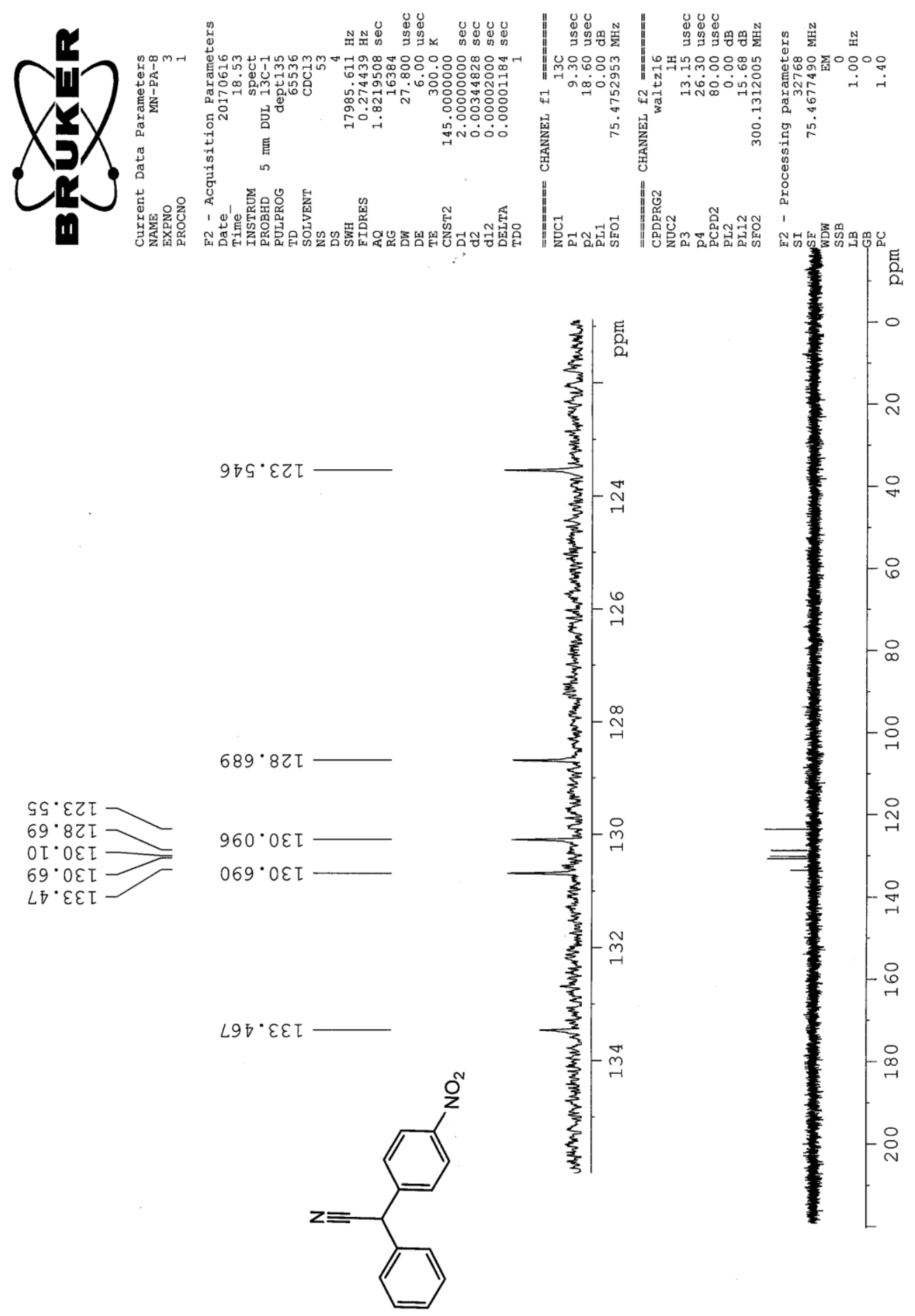

Volume 6 Issue 7, July 2017 www.ijsr.net 